\title{
Marketing Strategy Research for the Clothing Category on Mobile Terminal of E-commerce Platform
}

\author{
Ye Wang \\ Kyung Hee University, Seoul, Korea \\ 294244476@qq.com
}

Keywords: E-commerce platform; The mobile terminal; Apparel category; The marketing strategy

\begin{abstract}
With the number of mobile Internet users increased year by year, the development of a trend which cannot be halted in mobile e-commerce, and mobile providers have been developing clothing clothing brand and jointly promote the e-commerce platform. This article is from the perspective of e-commerce platform, e-commerce platform to study the mobile side, that is, e-commerce platform mobile APP, the marketing strategy in the apparel category. The purpose of this study is to prove that not the clothing category marketing strategy business platform mobile terminal completely copy the PC side, there are different types of business platform, and different types of mobile terminal business platform has different marketing strategies in the clothing category.
\end{abstract}

\section{Introduction}

In e-commerce platform (hereinafter referred to as electronic business platform), the clothing category refers to a variety of goods in the business platform operated by a variety of goods, the collection of all clothing. Clothing category, consistent with the concept of electronic business platform food category, home appliances category, is one of the first to achieve electricity supplier industry. Clothing category as one of the highest category of electricity supplier trading volume, as well as the characteristics of high margin and high purchase frequency, the major electricity supplier platform attaches great importance to. In the "Internet plus" trend, platform based electricity supplier is concerned, whether it is Tmall, vip.com or Jingdong, clothing retailers have to cooperate with the electricity supplier platform. Platform based electricity supplier platform integration platform have advantages and traffic advantages, the clothing retailer through cooperation and business platform, can find their own lack of product and operation ability from the perspective of the entire garment industry, is helpful to establish a long-term clothing business development concept, also help clothing electricity supplier industry as a whole upgrade. However, the rapid development of the electronic business platform, but also hide a lot of problems, the most prominent is the homogenization of electronic business platform. Homogenization of electronic business platform refers to the electricity supplier platform is almost the same on the goods, the marketing means to imitate each other, and ultimately the formation of homogenization of electronic business platform. In the context of this business platform, the development of the clothing category inevitably fall into the homogenization, including the explosion of products, selling brand, marketing means are almost the same, and such problems exist in the PC platform and mobile terminal. Based on the strategy of clothing category marketing platform to the mobile terminal as the research object, to explore the clothing category marketing strategy in the business platform of the mobile terminal and PC terminal in the analysis of the similarities and differences between different types of mobile electronic business platform, the specific use of garment marketing strategy category, and whether there are differences.

\section{Mobile Terminal and PC End Comparison}

Business platform in order to promote consumer purchase platform clothing as mass purchase frequency high selling category, to Internet marketing and apparel marketing combination, and implement effective marketing strategies, and ultimately contributed to the electricity supplier 
platform of apparel sales growth. Many large e-commerce platform has PC and mobile terminal synchronization operations, and two terminals in the marketing and marketing strategies are mostly the same. However, due to the characteristics of mobile devices, such as portable and easy to carry, not limited by time and space, the e-commerce platform in the mobile side of the clothing marketing strategy reflects some unique characteristics of the mobile terminal, and the different characteristics of the PC side. Through the comparison of the same e-commerce platform of the mobile terminal and PC terminal, and to the fixed business platform classification, marketing and interactive experience three aspects as the analysis object, we can be more specific about the clothing marketing strategy business platform for mobile terminals, fixed classification business platform of the mobile terminal and PC terminal at the entrance on the show is different, as the mobile terminal equipment is portable, users open platform in a day higher frequency, if the mobile terminal picture scroll timing update, will mobilize more interested users, it also brings more fresh feeling to the user.

Fixed classification of business platform of the mobile terminal and PC terminal in the two page display on the mobile terminal equipment is different, due to the small screen size of mobile phone users, browsing habits and PC client, and shopping in the mobile terminal time is more fragmented, so the mobile display logic, visual display and PC client end. Business platform marketing mode of the mobile terminal and PC terminal on sale is different, because the mobile terminal browser faster, marketing limited or special offer the special offer every day seckill regardless of single product category and brand, only the more obvious price advantage, relatively limited discount brand more simple, more quickly to seize the user attention, to promote the rapid purchasing. Electronic business platform marketing methods in the fixed marketing point of time on the mobile terminal and the PC side is different, due to the portable and portable mobile devices, the platform's evening viewing on the mobile terminal is higher than the PC side. To this end, the platform according to the mobile terminal to browse the evening peak, specially planned for the evening promotions. The interactive business platform experience in clothing collocation on different mobile terminal and PC terminal, the mobile terminal is as compared to the PC side is more convenient to interact with the user, the common behavior, and clothing collocation is the user in life, therefore, platform for the development of online clothing collocation function, is conducive to the increase of interactive user experience, is conducive to increasing mobile end user stickiness.

\section{Classification of Electronic Business Platform}

According to the classification of electronic business platform business platform's core business strategy, business platform for integrated business platform, vertical business platform, electronic business platform, cross-border sale of electronic business platform, and shopping guide class business platform.

Integrated Electronic Business Platform. The operation strategy of comprehensive electricity supplier platform is based on the operation of the whole category of products, for the most extensive user group characteristics, product coverage, platform services and a wide range, compared with other classification of the business platform can satisfy more consumers and suppliers demand. Integrated electronic business platform has a strong system support, such as marketing systems, payment systems, these systems have a full impact on the evaluation of consumers and suppliers of platform services. In addition to the platform system, the larger the size of the business platform, the more able to introduce more consumers, that is more platform traffic. Domestic large shopping platform, Tmall and Jingdong, are representative of the integrated class electronic business platform. With Tmall and the world's major brands jointly build a full channel, the gradual integration of online and offline growth, the number of Tmall platform consumers and purchasing power will grow. Tmall as the representative of the platform advantage products

Class of clothing for the class of electronic business platform is to promote innovation and development of domestic apparel e-commerce.

Vertical Class Electronic Business Platform. With the growing maturity of e-commerce platform, e-commerce market segments are gradually opened up, not only the formation of vertical 
areas of e-commerce, but also the formation of a vertical electronic business platform. Compared with the integrated large business platform, operation strategy of vertical business platform is the market segments of the electricity supplier services professional, meticulous, more able to meet the needs of industry segments and vendor specific consumer groups. Although the scale of business on the platform, it is difficult to exceed the total flow of integrated business platform, but the quality of the flow of more accurate, more suitable for mining potential needs of specific consumer groups, it can promote the development of the electricity supplier vertical segments. Vertical business platform focus on market segments and customer segmentation, can carry out precision marketing and service to users from a professional point of view, the comprehensive business platform while the category is very wide, but can not fully meet the individual needs of users. At present, the consumer is positioned in the vertical electronic business platform of the female group, which is designed to provide users with products and services related to women. The clothing platform such as the beautiful that star wardrobe, cosmetic platforms such as jumei.com, Lasafo, maternal and child class platform such as babe network, red child etc.. Vertical class electronic business platform compared to the class of electronic business platform has a stronger control, better shopping experience, but also to promote the maturity of the market segments.

The Sale of Electronic Business Platform. The sale operation strategy for business platform successfully stimulate consumer impulse shopping, their sale is more sensitive to the price to attract consumer groups to brand limited discount, single product promotions and promotions. Although the sale of the business platform in the form of promotion is very common, but there are a number of focus on sale, with only limited cheap way to seize the consumer electronic business platform, we can call them the sale of electronic business platform, such as vip.com, folded in 800, as street, volume leather mesh etc.Vip.com represents the sale of electricity supplier platform, regularly launch all kinds of brand discount merchandise, brand promotion of time in a professional sale page, because each sale is to limit the sale, also known as flash purchase form. Vip.com brand, discount, limit three elements to seize the consumers to buy low-priced products mentality, since its establishment in 2008, the number of registered members increased, finally in seven years to achieve the cumulative number of registered members exceeded 100 million. According to industry analysts, vip.com is not only effective operation in sale mode, but also in terms of brand goods, warehousing logistics, user experience is also rising, and provide important support for the long-term development of the platform. Another special sale of electronic business platform, clear street, sale business consists of 9 pieces of 9 bags of mail, brand flash sale, and got rapid development in 2015. Clearly street in product selection based entirely on 90 consumer groups consumption preference and consumption, and the cost of goods and quality of the shopping experience, the mobile APP number of active users is increasing gradually, to obtain a large number of 90 target users. Therefore, the long-term development of the sale of electricity supplier platform, not only need to actively try to sale, also need to enhance the support strength of the platform, such as products, logistics, marketing, user experience.

Cross-border Electronic Business Platform. E-commerce platform for cross-border e-commerce as the main operating strategy, we can call it a cross-border electronic business platform. Cross border electricity supplier platform by providing cross-border electricity supplier services, will be highly acclaimed foreign brands to introduce the Chinese market for domestic consumers to buy imported goods to provide a convenient. With the rise of cross-border electricity supplier, the domestic sea Amoy population is expanding, overseas maternal and child products, cosmetics, and apparel products are increasingly sought after by domestic consumers. Recent domestic popular cross-border electricity supplier platform, such as foreign terminals, scouring the world, NetEase koala sea purchase, honey bud and other imported electricity supplier platform, the main business of these platforms is cross-border electricity supplier business. Tmall international Jingdong, the global purchase, although Amazon overseas purchase is a platform business model of cross-border electricity supplier, but they are relatively large class integrated business platform, cross-border business is just one of the many business platform, so it is not included in the cross-border electricity supplier platform. As a small cross-border electricity supplier platform, 
ocean terminal, scouring the world platform for the supply chain with buyers and distributors, and to the community and guide the form of interaction with the user, further meet the needs of individual users. The future of cross-border electricity supplier platform should be the main force in the logistics speed, cross-border shopping experience, and the future of cross-border electricity supplier competition, not only the price competition, but also the ability to integrate the supply chain competition.

\section{Different Types of Electronic Business Platform Mobile Terminal Marketing Strategy}

Clothing Promotion There are a lot of business platform mobile terminal Clothing promotion mode, this paper only from the perspective of clothing sale. Clothing sale is a business platform to take limited preferential way to low-cost sales marketing strategy in the mobile terminal business platform mainly brand limited discount, single product shop, timed timed seckill full cut and other promotional benefits for clothing clothing sale. The clothing sale business platform with a certain theme often activities are organized and show, theme and Clothing promotion benefits are important contents of the publicity and promotion activities. Comprehensive electricity supplier platform and the sale of clothing sale level is very rich. In the case of Tmall, Tmall is China large B2C business platform, and belongs to the category of integrated business platform, with many domestic and foreign big clothing, clothing in the mobile terminal sale with mobile home brand sale and super brand. The main object of Tmall's services for large businesses and brand businesses or through brand licensing business, Tmall brand clothing sale mainly to the sale. Because the sale of electricity supplier platform dedicated to the limited cheap panic buying forms to attract consumers to high cost commercial pursuit, the main platform is that the operation strategy of sale, so clothing sale in the sale of electricity supplier platform clothing marketing strategy is one of the most important strategies. The sale of electricity supplier platform has two kinds, one is the "light luxury brands + limited discount" as the main way of sale, customer price high business platform, such as vip.com, glamour, Luxuries network, which is a kind of multi way sale combination, customer price low business platform, such as street. And rolling net, folded in 800. Like vip.com, glamour, LuxeHome network business platform although there are various irregular sale activities, but the clothing sale way is just to show the brand limited discount, brand sale countdown form. This single way of clothing sale highlights the characteristics of the platform, making a low price can buy high-quality goods flash sale atmosphere, the target consumer group has thus been locked in the white-collar and over consumption, therefore limited discount clothing can be around this target population of fashion preferences get hot. Another neat street, like volume leather mesh, fold 800 business platform in the clothing sale not only brand limited discount, and limited single product Limited cheap street such as panic buying, as the whole point of 9,9 and flash sale volume leather mesh of the latest discount and finally berserk, are sale form clothing items. By this kind of electronic business platform will target consumers in the 90 young people, students and people entering the workplace is a typical urban white-collar consumer groups, so this type of clothing business platform of low price, limited discount brand and limited preferential single product price is low, very much in line with the 90 people buying demand.

Clothing Category. The search is the classification of clothing business platform for clothing according to the attributes or features of clothing subdivision, is to provide clothing screening conditions for consumers, and to facilitate users to quickly and accurately screening to meet the needs of their clothing. There are a lot of clothing classification in the electronic business platform, such as clothing gender into men's, women's and children's clothing, or clothing styles according to the basic segmentation is divided into a jacket, trousers, skirt, or according to the clothing style, material, color, size, shape and other occasions, classification. A separate entrance to the "classification" named in the mobile terminal some business platform, this paper refers to the classification of clothing and not only refers to the "classification" is also included in the entrance, on the other end of the mobile platform on clothing classification, but also in various types of electronic business platform, clothing search classification in different ways. Now there are some fashion related vertical business platform focusing on the classification of clothing fashion clothing 
features itself, such as the beautiful dress, said assistant and Beijing are in fashion wardrobe by keywords for clothing classification basis, and provide consumers with a rich variety of clothing screening conditions. The classification of fashion clothing category vertical platform in addition to the basic styles of classification of clothing, there are more segments of the popular style classification, garment style classification, color classification, dressing effect classification, and the classification of dress occasions. The clothing in the fashion category vertical platform belongs to the core category, and in order to meet the audience the platform of fashion clothing classification in the deep pursuit of fashion vertical class business platform to the professional point of view of subdivision. In the positioning of different platforms, with the same class of vertical fashion business platform in the clothing category also have their own focus. For example, said the focus on the beauty of a comprehensive, sub fashion and popular fashion style clothing category, and the main category is done very carefully and refined. Clothing in order to classify the style of clothing is conducive to the collection and prediction of style data, but also conducive to the development of C2B model of beauty. The same type of clothing with the vertical fashion business platform assistant not only clothing style differentiation, but also from the perspective of clothing with a variety of matching with the classification, fully meet the needs of consumers with clothing. This is because the dressing assistant is committed to providing fashionable dress collocation services for women, since it is the collocation, requires different body characteristics of the variety of clothing and women's fashion attribute professional segments, can help the user to improve the efficiency of the collocation of clothing.

Comprehensive category of electronic business platform for the classification of clothing and vertical class electricity supplier platform is relatively simple, the general classification of the clothing of the current classification of the popular fashion clothing category, rather than from the more point of view of clothing. This is because the class integrated business platform in addition to clothing, there are many large retail categories, each big retail category requires a certain amount of manpower cost, the platform does not have a large enough scale, it is difficult for a single category do meticulous like vertical class business platform. At the same time, the development of a comprehensive class of electronic business platform, the overall development of the whole category, rather than relying solely on a category or a few categories, and therefore will not invest too much in a separate clothing category. Tmall clothing is the platform of the main categories, the advantage of category, but in this environment, Tmall clothing classification is also not too many segments, classification display mode is relatively simple, because Tmall belongs to the category of integrated business platform, not suitable for the classification of clothing do too complex, is not conducive to synchronization the development of other categories, and more emphasis on the sale of the way to attract consumers attention for clothing.

Costume Community. Fixed entrance in all types of electronic business platform of mobile terminal in the community is a common entrance, its business platform brings together the various common interests of users, users in the community on the topic of interactive discussion behavior data generated for business platform in product selection, marketing and so on. Due to the existence of trust relationship between users within the community, the community users hope that through the community sharing as the reputation of the product purchase decision, effectively increase the business platform for mobile end user activity, but also to some extent to improve the turnover rate of the commodity business platform. If the electricity supplier platform mobile terminal entrance into the community as a platform, and in a large community to establish a theme as the center of the group can be called a small community. In the end of the mobile platform in the community of electronic business platform on the topic of the group, we can be called in the platform of the community entrance of the clothing community. There are some similar social function in each business platform of mobile terminal in the community, for example, you can add your own interest in the community within the user's clothing or garment circle group, and can create or participate in the discussion topic. The social function of users to increase the viscosity, the entire electricity supplier platform of mobile terminal and business platform for the clothing category, clothing community enhances the user buy clothing desire, improve the transformation frequency of 
purchase platform clothing and apparel categories rate.

\section{Conclusion}

The current research on the mobile terminal marketing although increased, but in the mobile terminal business platform analyzes how to promote the development of the clothing category, how to optimize the research strategy clothing category marketing platform to the mobile terminal is not much, but the electricity supplier platform clothing category in the development of mobile terminal, is emerging in recent years, and as a result the limitations of the theoretical basis, cognitive level and time, the only reference to the relevant literature, and the author accumulated in the work experience, to the classification business platform as the starting point for the discussion, there are many details and problems need further study, and puts forward the conclusions and suggestions are to be in practice more verification and correction step by step.

\section{References}

[1] Tao Wu. China Mobile Internet users to 946 million, mobile Internet users over 900 million.[EB/OL].[2015-09-23].http://it.chinanews.com/it/2015/09-23/7540513.shtml

[2] Junhong He. Market driven strategy of mobile marketing[J].Enterprise vitality,2008.3.

[3] Songpo Liu. Research on brand marketing strategy of mobile Internet companies in China[D].Northeast Normal University.2012.

[4] Malik, Anjali., Kumra, Rajeev., and Srivastava, Vandana. Determinants of Consumer Acceptance of M-Commerce[J]. South Asian Journal ofManagement.Vol.20, (2), 102-126, 2013.

[5] Kenneth C.C. Yang. Exploring factors affecting the adoption of mobile commerce in Singapore[J].Telematics and Informatics ,Vol.22, 257-277, 2005.

[6] Mort, S.G. and Drennan, J. Mobile Communications: A Study of Factors Influencing Consumer Use of M-Services[J].Journal of Advertising Research,Vol.10,(2),302-312,2007.

[7] Song, J., Koo, C., and Kim, Y. Investigating Antecedents of Behavioral Intentions in Mobile Commerce[J], Journal of Internet Commerce, Vol. 6, (1), 13-34, 2007.

[8] Bhatti, Tariq. Exploring Factors Influencing the Adoption of Mobile Commerce[J]. Journal of Internet Banking and Commerce.Vol.12, (3), 1-13, 2007.

[9] Rakhi Thakur and Mala Srivastava. Customer Usage Intention of Mobile Commerce in India: an Empirical Study[J]. Journal of Indian Business Research.Vol.5(1), 52-72, 2013.

[10] Khalifa, Mohamed and Ning Shen, Kathy. Explaining the Adoption of Transactional B2C Mobile Commerce[J]. Journal of Computer Information Systems, Vol. 48, (3), 111-117, 2008. 